\title{
Efficacy of fine needle aspiration cytology in diagnosing soft tissue tumors
}

\author{
Parajuli $\mathrm{S}^{1}$, Lakhey $\mathrm{M}^{2}$ \\ ${ }^{I}$ Department of Pathology, Kathmandu Model Hospital, Kathmandu, Nepal \\ ${ }^{2}$ Department of Pathology, Kathmandu Medical College, Kathmandu, Nepal
}

\section{Keywords:}

Fine needle aspiration cytology;

Soft tissue tumors

\begin{abstract}
Background: Fine needle aspiration cytology has an established role in the diagnosis of various neoplastic and non-neoplastic lesions. Its accuracy when applied by experienced and well trained practitioners matches that of histopathology in providing an equivocal diagnosis; so it can also be used as a very useful alternative to excision biopsy in the diagnostic workup of soft tissue tumors.
\end{abstract}

Materials and Methods: This retrospective study was done in the Department of Pathology, Kathmandu Medical College for a period of one year from January 2006 to December 2006. A total of 60 cases presented with soft tissue tumors, of which only 50 were biopsied and the correlation done. A detailed history, clinical findings, routine relevant laboratory investigations and radiological findings were carried.

Results: Fine needle aspiration cytology revealed diagnostic materials in 47 cases and 3 cases were inconclusive for a definite diagnosis. 40 cases were diagnosed as benign lesions and 7 cases as malignant lesions. Out of the benign cases, the most common were lipomas which accounted for $52.5 \%$ of cases followed by benign mesenchymal tumor- $17.5 \%$. Out of the malignant cases $71.42 \%$ were diagnosed as malignant mesenchymal tumor and $28.57 \%$ as malignant nerve sheath tumor. The overall diagnostic accuracy of fine needle aspiration cytology in soft tissue tumors in the present study was $86 \%$. The sensitivity and specificity of diagnosing benign soft tissue tumors was $97.36 \%$ and $66.67 \%$ respectively and for malignant soft tissue tumors $66.67 \%$ and $97.36 \%$ respectively.

Conclusion: Fine needle aspiration cytology can be effective and reliable diagnostic tool in the evaluation of soft tissue tumors. It is highly sensitive to detect benign soft tissue tumors and highly specific for malignant soft tissue tumors.

\section{INTRODUCTION}

In general, the ratio of benign to malignant tumors is about 100:1 in a hospital population, and their annual incidence is approximately 300 per 100,000 populations. ${ }^{1-3}$

Fine needle aspiration cytology is a relatively non-traumatic procedure for sampling both the superficial and deep-seated

\section{Correspondence:}

Dr. Sharmila Parajuli, $M D$

Department of Pathology, Kathmandu Model Hospital, Kathmandu, Nepal. E-mail:drsharmi@hotmail.com masses. Multiple samples can be obtained in the same setting. The technique is relatively painless, produces a speedy result and is cheap. Fine needle aspiration cytology is well established technique for evaluation of epithelial tumors for many years. ${ }^{4}$ Now it has gained its reputation in the diagnostic work up of soft tissue tumors as well. ${ }^{3,4}$

However, the role of fine needle aspiration cytology (FNAC) in the initial diagnosis is still debatable, especially for soft tissue tumors although a number of articles published during recent years have indicated the value of FNAC as a 
pre-treatment diagnostic method. ${ }^{5,6}$ The diagnostic accuracy of FNAC of soft tissue tumors in distinguishing benign and malignant lesions is very high. ${ }^{7}$ The level of diagnostic specificity and sensitivity are approximately $95 \%$ for establishing a definite diagnosis of sarcomas. ${ }^{8}$

This study has been undertaken to increase our understanding about the soft tissue tumors, the sensitivity and specificity of FNAC in diagnosing soft tissue tumors, its cyto-architectural features and to compare these findings with histopathological diagnosis. ${ }^{9}$

\section{MATERIALS AND METHODS}

This was a prospective study conducted within a period of one year from the period of January 2006 to December 2006 in the department of pathology at Kathmandu Medical College Teaching Hospital. A total of 60 cases of clinically evident soft tissue swelling were taken for the study. Out of these, only 50 cases were selected and those were the patients who gave consent to undergo both the FNAC as well as biopsy. A detailed history, clinical findings, routine relevant laboratory investigations and radiological findings were carried out in each case. FNAC was done with 21 $\mathrm{G}$ needle attached to $10 \mathrm{ml}$ disposable plastic syringe. Smears were fixed in 95\% ethanol for 20 minutes and were then stained with Papanicolaou stain. Air-dried smears were stained with May Grunwald's Giemsa stain. The smears were studied for cytological details and diagnosis. The surgical excised specimens of the above cases were processed routinely and stained with Hematoxylin and Eosin stain and examined. A final correlation was done between cytological and histological diagnosis. Data was analysed using the Statistical Package for Social Science (SPSS, version 12) for Windows.

\section{RESULTS}

There were total of 50 cases of soft tissue tumors from January 2006- December 2006. FNAC revealed diagnostic materials in 47 cases and 3 cases were inconclusive. Forty cases were diagnosed as benign lesions, 7 as malignant lesions and 3 cases as inconclusive. The FNAC diagnoses of all cases are listed in Table 1 and 2. Out of the benign lesions, the commonest was Lipoma- 21 cases $(52.5 \%)$ followed by benign mesenchymal tumor- 7 cases (17.5\%). The commonest malignant tumor diagnosed on FNAC was malignant mesenchymal tumor- 5 cases $(71.47 \%)$ fowllowed by malignant nerve sheath tumor- 2 cases (28.57\%). Whereas the commonest benign tumor on histology was Lipoma- 19 cases $(48.71 \%)$ followed by Neurofibroma, Schwannoma and Tumoral Calcinosis- 4 cases each (10.25\%). Malignant fibrous histiocytoma was the commonest malignant tumor diagnosed on histology5 cases $(50 \%)$ followed by Dermatofibrosarcoma- 2 cases (20\%), leiomyosarcoma, alveolar soft part sarcoma and malignant schwannoma 1 case (10\%) each. Table 3 shows

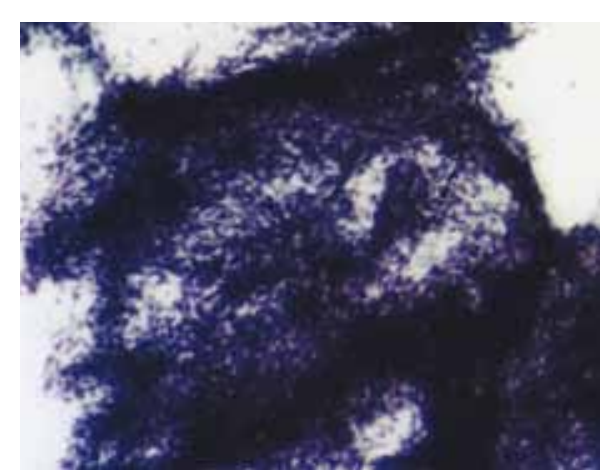

Figure 1: Benign mesenchymal tumor showing fragments of mesenchymal tissue (PAP stain, X100)

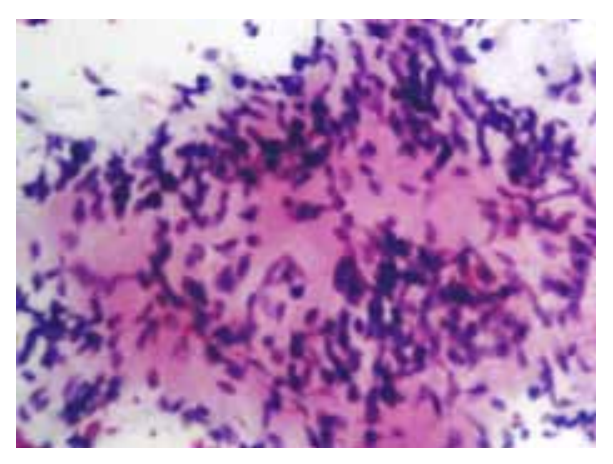

Figure 2: Benign nerve sheath tumor showing spindle cell proliferation (PAP stain, X100)

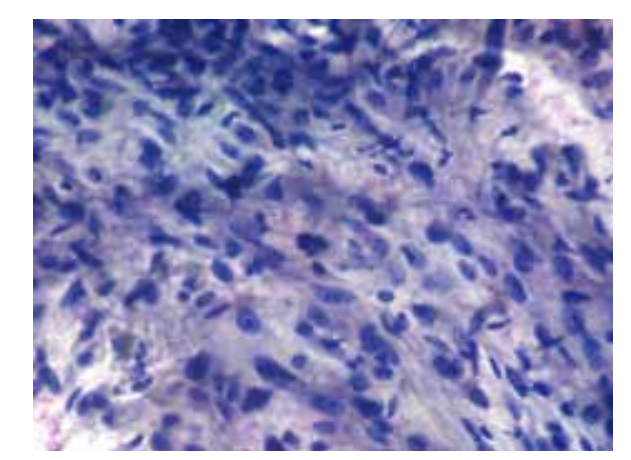

Figure 3: Malignant mesenchymal tumor showing pleomorphism of the tumor cells (PAP stain, X400)

the correlation between cytopathology and histopathology diagnosis of soft tissue.

The overall diagnostic accuracy of FNAC in soft tissue tumors in the present study was $86 \%$. The sensitivity and specificity of diagnosing benign soft tissue tumors was $97.36 \%$ and $66.67 \%$ respectively and for malignant soft tissue tumors $66.67 \%$ and $97.36 \%$ respectively.

\section{DISCUSSION}

FNAC has an established role in the diagnosis of various neoplastic and non-neoplastic lesions. Its accuracy when applied by experienced and well trained practitioners matches that of histopathology in providing an equivocal 
diagnosis, so it may also be used as a very useful alternative to excision biopsy in the diagnostic workup of soft tissue tumors. The two fundamental requirements on which the success of FNAC depends are representativeness of the sample and high quality of preparations.

Although it is very difficult to categorize the soft tissue tumors exactly by FNAC due to heterogenous nature of the soft tissue tumor as well as absence of tissue architecture in FNAC smears, thorough familiarity with these histological diversities of soft tissue tumors and experience with interpretation of different cell types in cytology smears are required to achieve high diagnostic accuracy in these tumors.

Our study have shown that out of the 50 cases, 40 were diagnosed as benign and 7 cases as malignant, thus accounting for the benign to malignant ratio of $6: 1$. The higher incidence of the malignant tumors in our case could probably be due to the greater size and a rapid increase in the size of the mass that might have led to seek medical attention and the need to do FNAC.

Our study shows that $80 \%$ of soft tissue tumors were benign on FNAC, out of which lipoma was the most common accounting for $52.5 \%$ cases followed by benign mesenchymal tumor $17.5 \%$. Various studies have shown the similar findings. ${ }^{3,4,10,11}$

Out of the 7 cases of malignant soft tissue tumors diagnosed on FNAC in our study, malignant mesenchymal tumor was found to be the commonest accounting for $71.42 \%(\mathrm{n}=5)$, further classification as malignant fibrous histiocytoma was given to $2 / 5$ cases. On excision biopsy, out of the 10 malignant cases, malignant fibrous histiocytoma was the commonest and accounted for 5 cases (50\%). Most of the studies have shown that malignant fibrous histiocytoma is the commonest malignant soft tissue neoplasm. Keith W. Bennert et $\mathrm{al}^{3}$ in their study of 37 cases of malignant soft tissue tumors have reported malignant fibrous histiocytoma as the commonest tumor accounting for $27 \%$ of cases. Similar Cannon Ersoz et $\mathrm{al}^{10}$ in their FNAC study of 52 soft tissue tumors have found that out of 32 malignant mesenchymal tumor, 5 cases (15\%) were malignant fibrous

Table 1: Distribution of benign lesions on Cytology

\begin{tabular}{lcc}
\hline Benign & No. of cases & Percentage (\%) \\
\hline Lipoma & 21 & $52.5 \%$ \\
Benign mesenchymal tumor & 7 & $17.5 \%$ \\
Benign fibrohistiocytic tumor & 3 & $7.5 \%$ \\
Tumoral calcinosis & 3 & $7.5 \%$ \\
Benign nerve sheath tumor & 3 & $7.5 \%$ \\
Benign spindle shaped tumor & 3 & $7.5 \%$ \\
\hline Total & 40 & $100 \%$ \\
\hline
\end{tabular}

Table 2: Distribution of Malignant tumors on Cytology

\begin{tabular}{lcc}
\hline Malignant tumors & No. of cases & Percentage (\%) \\
\hline Malignant mesenchymal tumour & 5 & $71.42 \%$ \\
Malignant nerve sheath tumour & 2 & $28.57 \%$ \\
\hline Total & 7 & $100 \%$ \\
\hline
\end{tabular}

Table 3: Correlation between cytopathological and histopathological diagnosis of soft tissue

\begin{tabular}{|c|c|c|c|c|c|c|c|c|c|c|c|c|c|c|c|c|}
\hline \multicolumn{17}{|c|}{ Diagnosis } \\
\hline FNAC diagnosis & $\begin{array}{l}\mathscr{E} \\
\tilde{E} \\
\tilde{\Xi} \\
\dot{0} \\
\dot{0}\end{array}$ & 芯 & 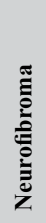 & 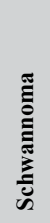 & 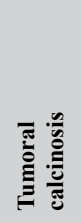 & 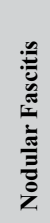 & 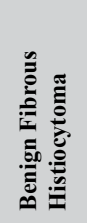 & 音 & ב气 & 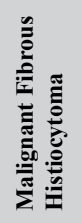 & 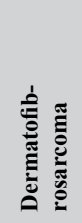 & 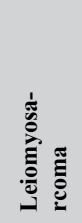 & 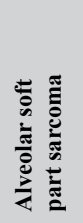 & 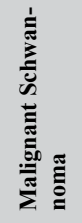 & 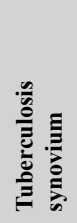 & हैँ \\
\hline Lipoma & 21 & 18 & 1 & 1 & & & & 1 & & & & & & & & 21 \\
\hline $\begin{array}{l}\text { Benign Mesenchymal } \\
\text { Tumor }\end{array}$ & 7 & 1 & 1 & 1 & & 1 & 2 & & & 1 & & & & & & 7 \\
\hline $\begin{array}{l}\text { Benign Fibrohistiocytic } \\
\text { Tumor }\end{array}$ & 3 & & & & & 1 & & 1 & & & 1 & & & & & 3 \\
\hline Tumoral Calcinosis & 3 & & & & 3 & & & & & & & & & & & 3 \\
\hline $\begin{array}{l}\text { Benign Nerve Sheath } \\
\text { tumor }\end{array}$ & 3 & & 1 & 2 & & & & & & & & & & & & 3 \\
\hline $\begin{array}{l}\text { Benign spindle Shaped } \\
\text { Tumor }\end{array}$ & 3 & & 1 & & & & & & 1 & & & 1 & & & & 3 \\
\hline $\begin{array}{l}\text { Malignant Mesenchymal } \\
\text { Tumor }\end{array}$ & 5 & & & & & & & & & 3 & 1 & & & & 1 & 5 \\
\hline $\begin{array}{l}\text { Malignant nerve sheath } \\
\text { Tumor }\end{array}$ & 2 & & & 1 & & & & & & 1 & & & & & & 2 \\
\hline Inconclusive & 3 & & & & 1 & & & & 1 & & & & 1 & & & 3 \\
\hline Total & 50 & & & & & & & & & & & & & & & 50 \\
\hline
\end{tabular}


histiocytoma.

FNAC has become an important diagnostic tool in the evaluation of soft tissue tumors. However, it has not been widely accepted because of concern about its diagnostic accuracy. The difficulties arise in exact typing and diagnosis of low grade sarcoma. But it gives fairly accurate results regarding the nature of lesion, especially when supported by appropriate clinical findings and radiological investigations.

In the present study, the reliability of FNAC in the diagnosis of benign and malignant soft tissue tumors compared to histopathological results was evaluated. The overall diagnostic accuracy of FNAC in soft tissue tumors in the present study was $80 \%$ and the sensitivity and specificity of diagnosing benign soft tissue tumors was $97.36 \%$ and $66.67 \%$ respectively and for malignant soft tissue tumors $66.67 \%$ and $97.36 \%$ respectively. Amongst 40 benign lesions diagnosed on FNAC, 37 were confirmed as benign on histopathology; where as the remaining 3(false negative $2.63 \%$ ) were diagnosed as malignant soft tissue tumor. Out of the 7 malignant lesions diagnosed on FNAC, 6 lesions were diagnosed the same, however one case diagnosed as malignant mesenchymal tumor on histology simply came out as tuberculosis of the synovium with $33.33 \%$ false positive results.

Lester J.Leyfield et $\mathrm{al}^{4}$ presented FNAC study of 136 primary soft tissue tumors with comparative histopathology results in 58 malignant and 42 benign lesions. They showed the diagnostic sensitivity of FNAC for detecting malignant neoplasm was $95 \%$ and specificity of $95 \%$. There were approximately $2 \%$ of false positive and false negative rate. Similar study of FNAC of soft tissue tumors in correlation with histopathology by Kulkarni DR et al. ${ }^{11}$ Comparative study of cytologic and histologic results of soft tissue tumors by Dey $\mathrm{P}$ et al $^{12}$ showed sensitivity and specificity $91 \%$ and $92 \%$ respectively, which were comparable with other studies. ${ }^{6,9}$ Other studies on FNAC of soft tissue tumors have shown high sensitivity and specificity. ${ }^{10,13,14}$

Different factors like poor localization of the lesions, poor aspiration techniques, tangential aspiration whereby the needle misses the tumor and only the inflammatory reaction are sampled, secondary changes like necrosis, haemorrhage and cystic change and desmoplastic tissue reaction which makes cells difficult to aspirate are the different factors leading to difficulty in adequate sampling of the tumor cells. Similarly, adequacy and representativeness of the smear material should be decided by the cytopathologist himself in order to give a definite opinion. Thus it is emphasized that FNAC should be carried out in diagnostic evaluation of soft tissue tumors with proper degree of attention to cytomorphological features, supplemented with clinical findings and other diagnostic data.

\section{CONCLUSION}

FNAC can be effective and reliable diagnostic tool in the evaluation of soft tissue tumors. It is highly sensitive to detect benign soft tissue tumors and highly specific for malignant soft tissue tumors. Since the technique is relatively painless, easy to perform and cheap, there are clear advantages to the patients, doctors and to the hospital. Its accuracy in many situations when applied by experienced and well trained practitioners, matches that of histopathology in providing an equivocal diagnosis.

\section{REFERENCES}

1. Markku Miettinen, Sharon, W. Weiss: In Soft tissue tumours. Anderson's pathology 10th edition 1996; Vol 2: pp480.

2. Gonzalez- Compora R, Munoz- Arias G, Otal- Solaverri C. Fine needle aspiration cytology of primary soft tissue tumors. Morphologic analysis of the most frequent types. Acta Cytologica 1992;36:905-17.

3. Bennert KW, Abdul-Karim FW. Fine needle aspiration cytology vs. needle core biopsy of soft tissue tumors: a comparison. Acta Cytologica 1994;38:381-4.

4. Layfield LJ, Anders KH, Glasgow BJ, Mirra JM. Fine needle aspiration of primary soft tissue lesions. Arch. Pathol lab med 1986;110:420-4.

5. Willen H; Akerman M; Carlen B- Fine needle aspiration in the diagnosis of soft tissue tumours; a review of 22 years experience. Cytopathology 1995;6:236-47.

6. Mirrales TG, Gonzelleza F, Menedez T. Fine needle aspiration cytology of soft tissue lesions. Acta Cytologica 1986;30:671-8.

7. Ricardo GC. Fine needle aspiration cytology of soft tissue tumours. Acta Cytologica 2002;46:337-43.

8. Barth RJ, Merino MJ, Solomon D: A prospective study of the value of core needle biopsy and Fine needle aspiration in the diagnosis of soft tissue masses. Surgery 1992;112:536-43.

9. Ackerman M. Idvall J, Anders R. Cytodiagnosis of soft tissue tumors and tumor like conditions by means of fine needle aspiration biopsy. Arch Orthop Trauma Surg 1981;96:61-7.

10. Canon Ersoz, Serdar Ozbarias, Ozlem Aydin.Fine needle aspiration of soft tissue tumors. Ann Med Sci 1998;7:111-5.

11. Kulkarni D R, Hemant R, Kokandaker et al. Fine needle aspiration cytology of soft tissue tumors in correlation with histopathology. Indian J pathol, Microbiol.2002;45:45-8.

12. Dey P, Malik MK. Role of fine needle aspiration cytology in the diagnosis of soft tissue tumors and the tumor-like lesions. Cytopathology 2004; 15:32-7.

13. Wakely PE Jr, Kneisl JS. Soft tissue aspiration cytopathology. Cancer 2000;90:292-8.

14. Amin MS, Luqman M. Fine needle aspiration biopsy of soft tissue tumors. J coll Physicians Surg Pak 2003;13:625-8. 